\title{
Nabokov's Lolita: Externalization of Contemporary Mind in the Configuration of Hedonistic Aesthetics
}

\author{
Saima Murtaza
}

\begin{abstract}
Ethics and aesthetics have invariably remained the two closely integrated artistic appurtenances for the production of any work of art. These artistic devices configure themselves into a complex synthesis in our contemporary literature. The labyrinthine integration of ethics and aesthetics, operating in the lives of human characters, to the extent of transcending all limits has resulted in an artistic puzzle for the readers.

Art, no doubt, is an extrinsic expression of the intrinsic life of man. The use of aesthetics in literature pertaining to human existence; aesthetic solipsism, has resulted in the artistic objectification of these characters. The practice of the like aestheticism deprives the characters of their souls, rendering them as mere objects of aesthetic gaze at the hands of their artists-creators. Artists orchestrate their lives founding it on a plot which deviates from normal social and ethical standards. Their perverse attitude can be seen in dealing with characters, their feelings and the incidents of their lives. Morality is made to appear not as religious construct but as an individual's private affair. Furthermore the idea of beauty incarnated, in other words hedonistic aesthetic does not placate a true aesthete.

Ethics and aesthetic are the two most recurring motifs of our contemporary literature, especially of Nabokov's world. The purpose of my study is to peruse these aforementioned motifs in Nabokov's most enigmatic novel Lolita, a story of pedophilia, which is in fact reflective of our complex individual psychic and societal patterns. The narrative subverts all the traditional and hitherto known notions of aesthetics and ethics.

When applied to literature, aesthetic does not simply mean 'beautiful' in the text. It refers to an intricate relationship between feelings and perception and also incorporates within its range wide ranging emotional reactions to text. The term aesthetics in literature is connected with the readers whose critical responses to the text determine the merit of any work to be really a piece of art. Aestheticism is the child of ethics. Morality sets the grounds for the production of any work and the idea of aesthetics gives it transcendence. Keywords: Ethics, Aesthetics, Aesthetic Hedonism, Nymphet Syndrome, Pedophilia
\end{abstract}


